\title{
Moving towards a universal hepatitis $B$ vaccine program for Canadian children
}

$\mathrm{B}$ Y THE EARLY 1990S, EVIDENCE HAD ACCUMULATED THAT THE selective hepatitis $B$ vaccine strategy aimed at high risk individuals was failing to stem the tide of hepatitis $B$ infection in Canada. The reported rates of acute hepatitis $B$ and deaths due to hepatitis $B$ infection had increased, not decreased, over the decade (1). Both the National Advisory Committee on Immunization and the Canadian Paediatric Society, on review of the data and examination of possible factors behind the failure of the selective vaccine program (2), endorsed the principle of universal childhood immunization $(3,4)$.

The Canadian Hepatitis B Working Group, on reviewing the options (the status quo; universal infant program; universal preadolescent program; universal adolescent program), recommended that a preadolescent program be added to the current selective strategy to decrease the rate of new hepatitis B infection in Canada (5). Using American data, Bloom and colleagues (6) showed that the preadolescent school-based option is likely to be the most cost effective. This assessment is thought also to be valid in Canada since fewer than $3 \%$ of reported acute hepatitis B cases occur in early childhood, with the dramatic increase in incidence occurring in later adolescence and young adulthood. Given these demographics, sexual activity and possibly also injection drug use appear to be important factors for hepatitis $B$ transmission in Canada $(1,5)$. Thus, to maximize the impact on the incidence of hepatitis $B$ infection, a universal immunization program needs to begin before the onset of sexual activity. An adolescent program may be too late and a preadolescent program would have a shorter lag phase before accruing benefits than would an infant program. A preadolescent program has the added advantage of needing smaller doses of vaccine than an adult

All material presented in Paediatric Infectious Disease Notes has been reviewed and approved by the chairperson, Canadian Paediatric Society Board and representative members of the Canadian Pediatric Society Committee on Infectious Diseases and Immunization

Correspondence and reprints: Infectious Diseases and Immunization Committee, Canadian Paediatric Society, 401 Smyth Road, Ottawa, Ontario K1H 8L1. Telephone (613) 737-2728, Fax (613) $737-2794$ program while still offering protection before sexual activity becomes common.

British Columbia, the first province to introduce a universal preadolescent hepatitis B program, initiated a school-based program in 1992, which immunized over $90 \%$ of eligible 11 year-olds (7). Quebec, Yukon and Ontario followed suit with universal preadolescent school-based programs in 1994 aimed at grade 4 (Quebec and Yukon) and grade 7 (Ontario) students. Nova Scotia, New Brunswick, Newfoundland, Prince Edward Island, Alberta and the Northwest Territories are expected to have preadolescent school-based programs in place by the fall of 1995. New Brunswick, Prince Edward Island and the Northwest Territories have also started universal infant hepatitis $B$ immunization programs in addition to the preadolescent programs.

While all of the provinces and territories that have started the universal school-based programs must be applauded, this single grade/age strategy has created some confusion for the general public. Why are older children and adolescents not being covered since they will be moving into the sexually active risk group sooner than the eligible preadolescents? Cost appears to have precluded catch-up programs for adolescents at the moment. To facilitate immunization for adolescents and young adults who missed out on the school program, physicians in practice are encouraged to offer hepatitis $B$ immunization at cost through their offices. Both of the manufacturers of the currently licensed hepatitis $B$ vaccines have bulk purchase programs available to physicians, which can lower the cost for families by negating the additional dispensing fee charges of retail pharmacies. Some parents may be able to have the cost covered though private insurance if the vaccine is purchased by prescription. The direct line for Merck Frosst Canada Inc for Recombivax is 1-800-268-4827, and the direct line to SmithKline Beecham Pharma Inc for Engerix $B$ is 1-800-565-5468. In some provinces parents are also able to purchase vaccine at cost through their health department. Routine prevaccination screening for antibody is not recommended in this population because of the low prevalence of anti-HBS (hepatitis B surface antigen) (8). Postvaccination testing for anti-HBS in healthy persons is also not 
recommended provided that the vaccine was administered properly (8).

The lack of universal 'free' catch-up programs is of concern. The longer the delay in achieving a universally immunized adolescent population, the more new cases of hepatitis $B$ will likely occur and the less confidence the public will have in the program. Our provincial ministries of health must look closely at measures to expand coverage beyond these preadolescent school-based programs. Unfortunately, a universal health care system in which prevention programs receive high priority is still a long way from reality in Canada (9).

\section{REFERENCES}

1. Delage G, Carter AO. Hepatitis B infection in Canada. Epidemiology and implications for control. Can Fam Physician 1992;38:2656-6.

2. Alter MJ, Hadler SC, Margolis HS, et al. The changing epidemiology of hepatitis B in the United States. JAMA 1990;263:1218-22.

3. National Advisory Committee on Immunization. Statement on universal immunization against hepatitis B. Can Dis Wkly Rep 1991;17:165-72.

4. Infectious Disease and Immunization Committee, Canadian Paediatric Society. Hepatitis B in Canada: the case for universal immunization. Can Med Assoc J 1992;146:25-8.
5. Hepatitis Working Goup. Report of the Hepatitis Working Group. Can Dis Wkly Rep 1994;20:105-12.

6. Bloom BS, Hellman AI, Fendrick AM, et al. A reappraisal of hepatitis $B$ virus vaccination strategies using cost-effectiveness analysis. Ann Intern Med 1993;118:298-306.

7. Dobson SR, Scheifele DW, Bell A. Evaluation of a universal hepatitis $B$ vaccination program for adolescents in British Columbia. Pediatr Res 1993;33:167A. (Abst 982)

8. National Advisory Committee on Immunization. Canadian Immunization Guide, 4th edn. Ottawa: Health Canada, 1993:46-57.

9. Infectious Disease and Immunization Committee, Canadian Paediatric Society. Health care budgets and vaccine programs: a time for review and prioritization. Can Med Assoc J 1994;150:1555-6.
NE MacDonald MD FRCPC Chief, Division of Infectious Disease Children's Hospital of Eastern Ontario Ottawa, Ontario 


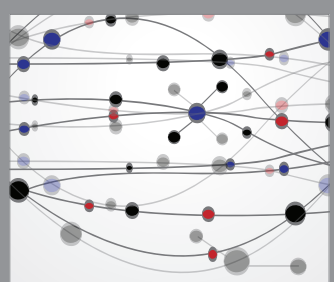

The Scientific World Journal
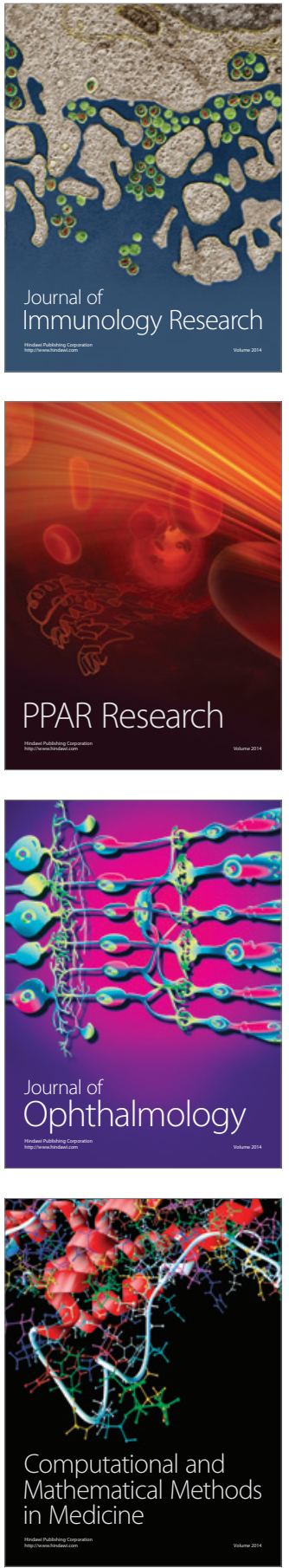

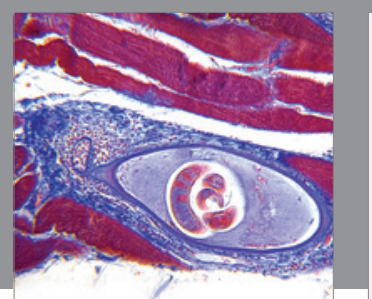

Gastroenterology Research and Practice

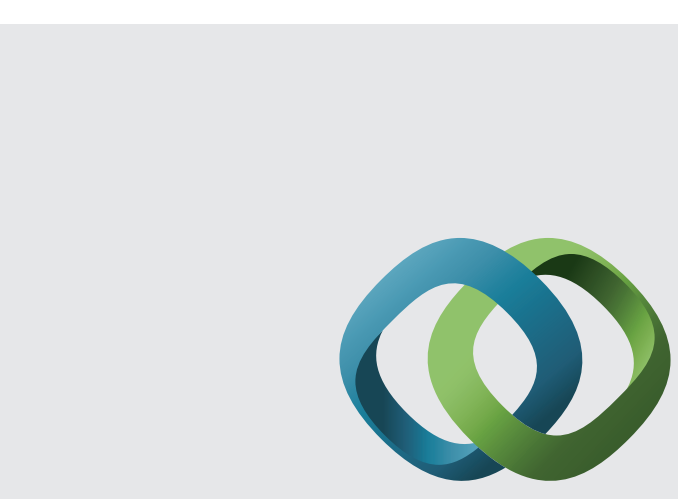

\section{Hindawi}

Submit your manuscripts at

http://www.hindawi.com
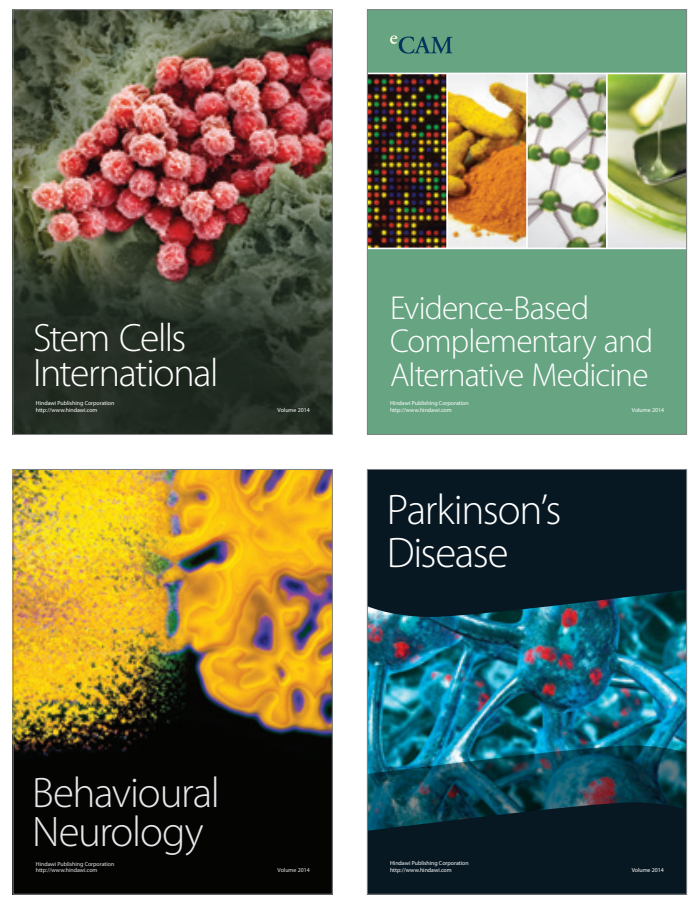
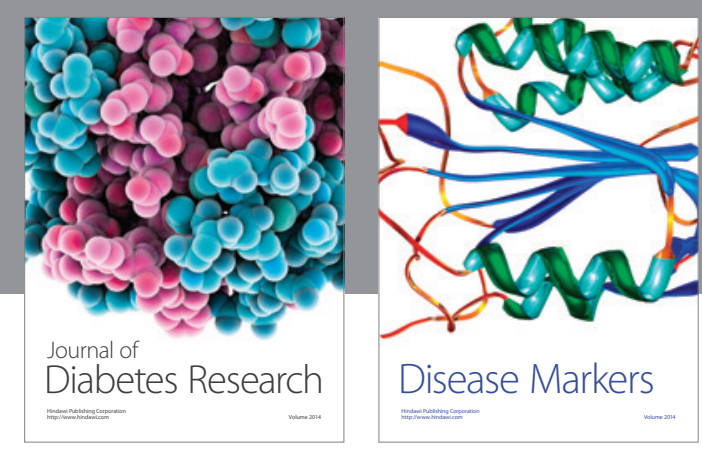

Disease Markers
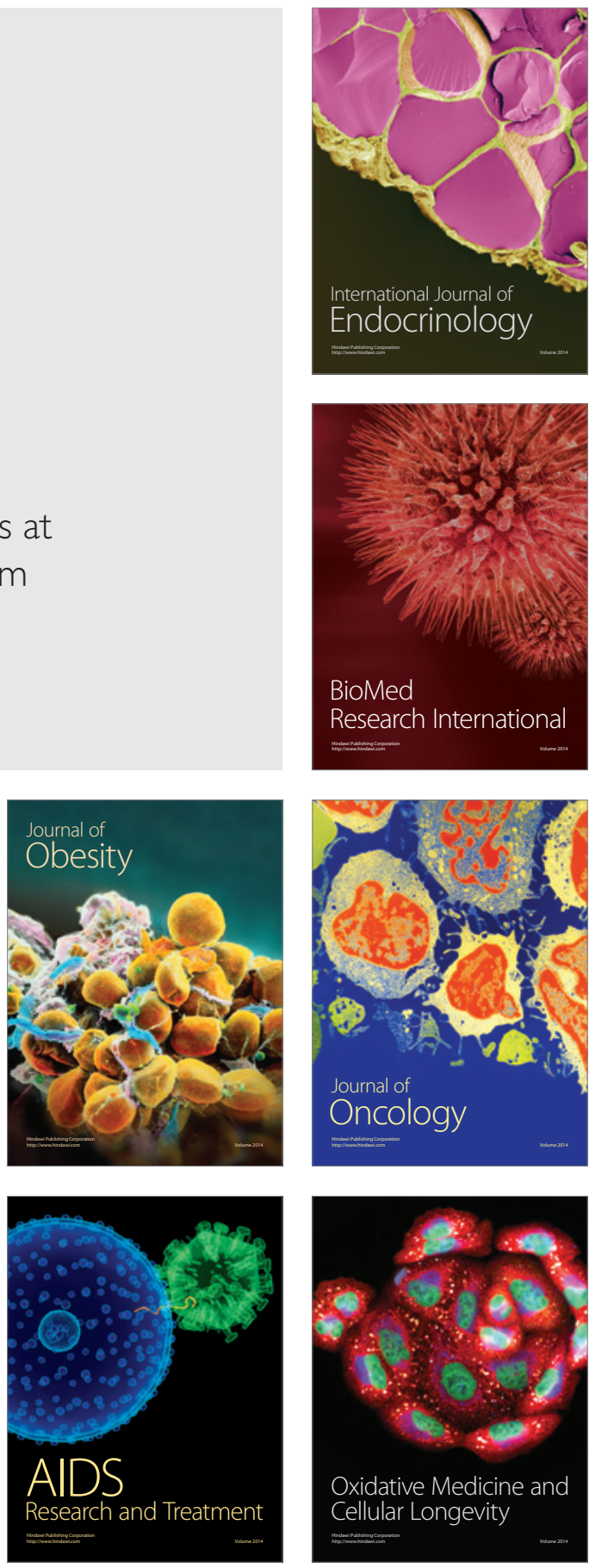